\title{
Representing the root water uptake process in the Common Land Model for better simulating the energy and water vapour fluxes in a Central Asian desert ecosystem
}

\author{
L. Li ${ }^{\mathrm{a}, \mathrm{b}, *}$, C. van der Tol ${ }^{\mathrm{b}}, \mathrm{X} . \mathrm{Chen}^{\mathrm{a}}$, C. Jing ${ }^{\mathrm{a}, \mathrm{c}}, \mathrm{B} . \mathrm{Su}^{\mathrm{b}}, \mathrm{G} . \mathrm{Luo}^{\mathrm{a}}, \mathrm{X}$. Tian ${ }^{\mathrm{d}, \mathrm{b}}$ \\ a State Key Laboratory of Desert and Oasis Ecology, Xinjiang Institute of Ecology and Geography, Chinese Academy of Sciences, Urumqi, China \\ ${ }^{\mathrm{b}}$ Faculty of Geo-Information Science and Earth Observation (ITC), University of Twente, Enschede, The Netherlands \\ ${ }^{c}$ Graduate School, Chinese Academy of Sciences, Beijing, China \\ ${ }^{\mathrm{d}}$ Institute of Forest Information Resource Techniques, Chinese Academy of Forestry, Beijing, China
}

\section{A R T I C L E I N F O}

\section{Article history:}

Received 8 November 2012

Received in revised form 15 July 2013

Accepted 19 August 2013

Available online 24 August 2013

This manuscript was handled by Andras

Bardossy, Editor-in-Chief, with the

assistance of Purna Chandra Nayak,

Associate Editor

\section{Keywords:}

Root water uptake efficiency

Land surface modelling

Desert shrubs

Evapotranspiration

\begin{abstract}
S U M M A R Y
The ability of roots to take up water depends on both root distribution and root water uptake efficiency. The former can be experimentally measured, while the latter is extremely difficult to determine. Yet a correct representation of root water uptake process in land surface models (LSMs) is essential for a correct simulation of the response of vegetation to drought environment. This study evaluates the performance of the Common Land Model (CLM) to reproduce energy and water vapour fluxes measured with an eddy covariance system in a Central Asian desert ecosystem. The default CLM appears to be able to reproduce observed net radiation, soil subsurface temperature, and wet period latent $\left(Q_{\mathrm{e}}\right)$ and sensible heat $\left(Q_{h}\right)$ fluxes, but significantly underestimate $Q_{\mathrm{le}}$ and overestimate $Q_{\mathrm{h}}$ during dry period. Underestimation of $Q_{\mathrm{le}}$ is attributed to the inappropriate representation of root water uptake process in the CLM model. Modifying the original root water uptake function (RWUF) with a linear function of soil water potential to one with an exponential function significantly improves the performances for both $Q_{\mathrm{le}}$ and $Q_{\mathrm{h}}$. The net radiation and ground heat flux simulations did not change noticeable with the new RWUF. It is concluded that an exponential RWUF is a valuable improvement of the CLM model and likely for other similar LSMs that use a linear RWUF for Central Asian desert ecosystems.
\end{abstract}

(c) 2013 Elsevier B.V. All rights reserved.

\section{Introduction}

Quantitative assessment of energy and water fluxes is essential to understand the complex interactions between land surface and the atmosphere (Kustas et al., 1996). Land surface models (LSMs) describing plant physiological behaviour in relation to soil and atmospheric processes have been widely used to estimate the energy and water fluxes (Bonan, 1996). Roughly 50 LSMs have been published during the last few decades, and this number is increasing every year. This indicates the general recognition of the importance of land processes in modern climatic, ecological and hydrological research (Dai et al., 2003). LSMs typically serve as a critical component (usually the lower boundary) of global carbon cycle models or generic circulation models (GCMs) for assessing and predicting the likely impacts of climate change and anthropogenic forcing on terrestrial ecosystems and their feedbacks.

* Corresponding author. Address: State Key Laboratory of Desert and Oasis Ecology, Xinjiang Institute of Ecology and Geography, Chinese Academy of Sciences, No. 818 Beijing South Road, Urumqi 830011, China. Tel.: +86 991788 5401; fax: +86 9917885320.

E-mail address: lhli@ms.xjb.ac.cn (L. Li).
More than 950 site years eddy covariance (EC) data have been archived in the international network of FLUXNET (Williams et al., 2009). The amount of EC data is still climbing year by year. The increase in EC data obtained from various terrestrial land surfaces facilitates research into poorly represented or missing ecosystem processes in models, leading to improvements of the model's performance (Baldocchi et al., 2001; Baker et al., 2008; Stockli et al., 2008; Williams et al., 2009; Choi et al., 2010; Schwalm et al., 2010; Li et al., 2011b). Commonly used LSMs include SiB (Sellers et al., 1986), Common Land Model (CLM) (Dai et al., 2003), ORCHIDEE (Krinner et al., 2005), CABLE (Kowalczyk et al., 2006) and their updated versions (Sellers et al., 1996; Wang et al., 2010; Bonan et al., 2011). These LSMs have been evaluated at different ecosystems including cropland, closed shrublands, deciduous broadleaf forest, evergreen broadleaf forest, evergreen needleleaf forest, grassland, mixed forest, open shrublands, savanna, wetlands, and woody savannah (Williams et al., 2009; Wang et al., 2012). LSMs are also widely used for groundwater use, runoff or soil moisture in hydrological research (Ridler et al., 2012; Zampieri et al., 2012; Zhou et al., 2012). The evaluations showed that LSMs have good ability to simulate the energy, water vapour and $\mathrm{CO}_{2}$ fluxes at the majority of the flux sites in global FLUXNET 
(Schwalm et al., 2010). Some of LSMs are even able to well capture the effects of occasional large scale or seasonal drought on ecosystem functions (carbon and water fluxes) (Ciais et al., 2005; Li et al., 2012).

Although the majority of the key processes controlling the energy and mass exchange between the terrestrial ecosystems and the atmosphere have been described in sufficient detail in the current LSMs to reproduce the fluxes, applications of LSMs in some ecosystems were found to be not successful. The ability to simulate energy and gas exchange in drought conditions remains especially limited. For example, IBIS and TEM (Saleska et al., 2003), SiB3 (Baker et al., 2008), and CABLE (Li et al., 2012) all required modification before they could reproduce the observed latent heat flux and net ecosystem exchange in Amazon forest where rainfall varied seasonally and obvious wet and dry seasons appeared. Some ecophysiological or ecohydrological processes such as modified root water uptake function (RWUF) and hydraulic redistribution must be reformulated or incorporated into the model to improve the model's performance (Baker et al., 2008; Li et al., 2012). The essence is that the plants may have adopted to the seasonality of rainfall by means of morphological adjustment in developing rich and deep root systems for utilizing deep soil water during dry season (Davidson et al., 2011), and this is notoriously difficult to model.

The roots of plants could impact transpiration by means of two aspects. One is the root depth and its vertical distribution in the soil profile. Another is the efficiency of absorbing soil water. The former could be reasonably obtained with experiment. The latter, however, is hard to describe. In majority of LSMs, root water uptake efficiency is formulated with empirical functions of root fraction and soil water content (Lai and Katul, 2000; Feddes et al., 2001; Li et al., 2006; Zheng and Wang, 2007). One of known deficiencies of some LSMs (for example CABLE) is the underestimation of latent heat flux due to inappropriate description of root water uptake process (Baker et al., 2008; Li et al., 2012).

The availability of soil water is a limiting factor for plant transpiration in Central Asia (CA) desert shrubs. Limited by climate with extremely low precipitation and humidity and high summer temperature, the dominantly distributed species Tamarix ramosissima in CA have evolved to have rich and deep root systems and high root/shoot ratio (Xu and Li, 2008), in adaptation to extreme aridity and heat conditions. Ecophysiological characteristics of the CA desert shrub do not significantly respond to rainfall (Xu et al., 2007), suggesting that morphological adjustment associated with the ecophysiological regulation of photosynthesis and transpiration with rich-developed root systems is important. Morphological changes (for example root/shoot ratio) tend to be the primary reaction which mitigates the effects of droughts in drought environment (Susiluoto and Berninger, 2007).

These effects of drought on root water uptake are not described well in current LSMs. It is unknown how well LSMs predict the fluxes in the CA desert ecosystem, since this has, to our knowledge, not been studied. The first objective of this research is to conduct a critical evaluation of CLM against EC data of a representative desert shrub ecosystem in CA area. The second objective of this research is to represent the RWUF in the CLM model for improving the model's performance in simulating the energy and water vapour fluxes in a Central Asian desert ecosystem.

\section{Material and methods}

\subsection{Site description}

A set of EC instruments has been established by the Chinese Academy of Sciences to monitor the energy, water and $\mathrm{CO}_{2}$ fluxes at Fukang Station of Desert Ecology (FSDE, $44^{\circ} 17^{\prime} \mathrm{N}, 87^{\circ} 56^{\mathrm{E}} \mathrm{E}$,
$475 \mathrm{~m}$ a.s.l., Fig. 1) The site is representative of desert ecosystem in Central Asia. The station is located at the southern periphery of the Gubantonggut Desert. Soil is a saline-alkali gault of moderate salinity, with $71 \%$ sand and $21 \%$ clay. The research area is mostly characterized by hot summers and cold winters with low annual precipitation. Historical mean annual precipitation is $163 \mathrm{~mm}$ and mean annual air temperature is $6.6^{\circ} \mathrm{C}$. The dominant vegetation is the desert shrub $T$. ramosissima, characterized by deep root systems, with a small proportion of herbaceous species including Salsola nitraria and Suaeda acuminate. Average height of Tamarix is approximately $1.75 \mathrm{~m}$. Within the area of $5000 \mathrm{~m}$ around the site, some proportion of dryland irrigated cropland is distributed.

The EC system consisted of a three-dimensional ultrasonic anemometer thermometer (STA-5055, KAIJO Corporation, Tokyo, Japan) and an open path infrared gas $\left(\mathrm{CO}_{2} / \mathrm{H}_{2} \mathrm{O}\right)$ analyzer ( $\mathrm{LI}-7500$, LI-COR, USA). The instrument was installed at a height of $3 \mathrm{~m}$ above the ground, and measurements were made with a frequency of $10 \mathrm{~Hz}$ and integrated as half-hour averages in the CR23X datalogger (Campbell Scientific, USA). The ground heat flux was measured with a heat flux plate installed at $5 \mathrm{~cm}$ below the soil surface. Recorded half-hour fluxes has been corrected using the WPL method (Webb et al., 1980). The ground heat flux at $5 \mathrm{~cm}$ below the soil surface was corrected to the surface based on the soil temperature gradient approach proposed by van der Tol (2012). The EC system also measured meteorological variables, including downward long wave radiation, downward short wave radiation, wind speed, pressure, air temperature, specific humidity, which were used to force the CLM model. Data from 2007 to 2009 were used in the current research.

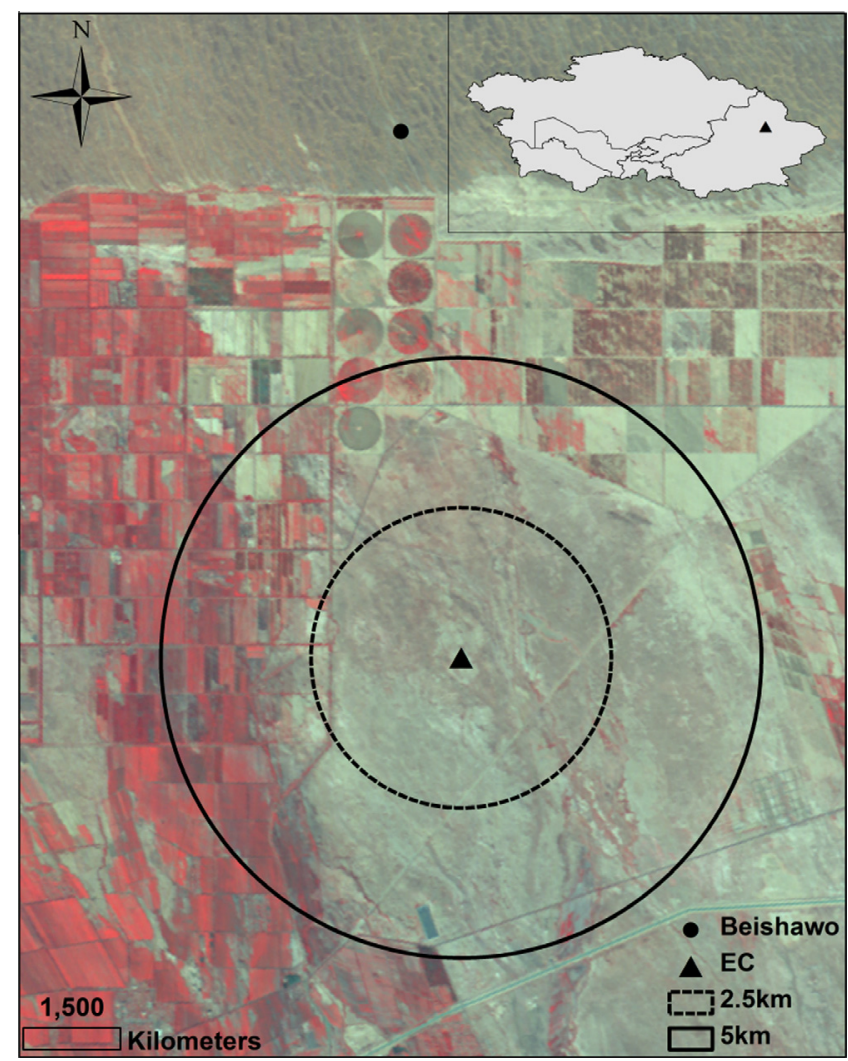

Fig. 1. Location of the eddy covariance (EC) site in Fukang, Xinjiang $\left(44^{\circ} 17^{\prime} \mathrm{N}\right.$ $87^{\circ} 56^{\prime} \mathrm{E}, 475 \mathrm{~m}$ a.s.l.) and map of the surrounding desert shrubs and irrigated croplands. The inner and outer rings show 2.5 and $5 \mathrm{~km}$ distance from the EC instruments. 
The high salinity of soil, strong dust, and power outage caused occasional malfunctioning of the EC equipment. To obtain fully calendar yearly meteorological data required by the model, missing variables except long wave radiation at FSDE site were replaced with the corresponding variables measured at another site Beishawo (BSW, $44^{\circ} 22^{\prime} \mathrm{N}, 87^{\circ} 55^{\prime}, 448 \mathrm{~m}$ a.s.l.) where climate was highly similar to FSDE. The distance between the two sites was around $5 \mathrm{~km}$, and no significant topographic difference existed. Missed long wave radiation data was calculated based on the formula proposed by Idso (1981).

\subsection{Common Land Model (CLM)}

By combining the best features of the land surface model (Bonan, 1996), BATS (Dickinson et al., 1993) and IAP94 (Dai and Zeng, 1997), CLM was originally developed for weather forecast and climate studies (Dai et al., 2003). CLM has been widely used to simulate the energy, water vapour and $\mathrm{CO}_{2}$ fluxes from the land surface (Zheng and Wang, 2007; Choi et al., 2010), and it has been coupled to GCMs for climate research (Zeng et al., 2002; Steiner et al., 2005). Although the CLM model has been updated by the modelling community (Maxwell and Miller, 2005; Oleson et al., 2008; Rihani et al., 2010; Zampieri et al., 2012), its core sub-modules remained unchanged.

The basic version of CLM (Dai et al., 2003) with a two-big leaf model for canopy temperature, photosynthesis, and stomatal conductance scheme (Dai et al., 2004) has been used in this research. In CLM, the total surface evapotranspiration consists of evaporation from wet stems and leaves, transpiration through the plant $T$, and initial evaporation from the ground (i.e., bare soil or snow surfaces). The calculations for stem and leaf evaporation and transpiration are similar to those used in BATS, while Philip's (1975) formulation is used for the computation of soil evaporation. A detailed description of CLM can be found in, for example Dai et al. (2003), but in many other papers as well. Only some parts related to soil water movement and root water uptake process were described here.

Water movement in soil was calculated by Darcy's law:

$\frac{\partial \theta}{\partial t}=-\frac{\partial}{\partial z}\left(K-D \frac{\partial \theta}{\partial z}\right)-E_{\mathrm{x}}$

where $\theta$ is soil water content $\left(\mathrm{m}^{3} \mathrm{~m}^{-3}\right), K$ is hydraulic conductivity $\left(\mathrm{m} \mathrm{s}^{-1}\right), D$ is soil moisture diffusivity $\left(\mathrm{m}^{2} \mathrm{~s}^{-1}\right), z$ is soil depth $(\mathrm{m})$, and $t$ is time (s).

The sink term $E_{\mathrm{x}}\left(\mathrm{m} \mathrm{s}^{-1}\right)$ is calculated as root water extraction from soil layer (also including soil evaporation for the first top soil layer). Total transpiration $(T)$ is allocated to each soil layer $(i)$ by a fraction $\eta_{i}$ :

$E_{\mathrm{x}}=T \eta_{i}$

It is noteworthy that both $T$ and $\eta_{i}$ are impacted by soil water availability. The fraction $\eta_{i}$ is estimated as

$\eta_{i}=\frac{f_{\mathrm{root}, i} f_{\mathrm{sw}, i}}{\sum_{i=1}^{n} f_{\mathrm{root}, i} f_{\mathrm{sw}, i}}$

where $n$ is the total number of soil layers, $f_{\text {root }, i}$ and $f_{\mathrm{sw}, i}$ are the root fraction and soil water availability in the $i$ th soil layer, respectively. The fraction $f_{\mathrm{sw}, i}$ is assumed a linear proportion of soil water matric potential $\left(\varphi_{i}, \mathrm{~mm}\right)$ :

$f_{\mathrm{sw}, i}=\frac{\varphi_{\max }-\varphi_{i}}{\varphi_{\max }+\varphi_{\mathrm{sat}}}$

where $\varphi_{\max }$ is the potential at the wilting point (set to $-1.5 \times 10^{5} \mathrm{~mm}$ ), and $\varphi_{\text {sat }}$ the soil water matric potential at satura- tion. The value of $\varphi_{\text {sat }}$ depends on soil texture, and $f_{\mathrm{sw}, i}$ is thus a linear scale from 1 when at saturation, to 0 at wilting point.

There is evidence (Zheng and Wang, 2007) that the fact that $f_{\mathrm{sw}, i}$ is a linear function of $\varphi_{i}$ causes an underestimate of evapotranspiration under when water stressed conditions. Lai and Katul (2000) found that the efficiency of root water uptake changed with water availability: the efficiency was the highest in the wettest part of the root profile, and deep roots can take over the role of shallow roots if the top soil dries out. More realistic and nonlinear response curves between root water uptake efficiency and soil water availability were proposed (Lai and Katul, 2000; Li et al., 2006; Zheng and Wang, 2007) and some of them were found very useful for some other LSMs (Li et al., 2006, 2012) but few have been incorporated into the CLM and applied to a desert environment. One of the most significant features of a desert environment is the low soil moisture content during the growing season. Previous research have found that deep roots have water transport conduits with much greater diameters and therefore, higher hydraulic conductivity compared with shallow roots or stems (Jackson et al., 2000; McElrone et al., 2004). Based on the understanding on the mechanisms and modelling of root water uptake, we propose a simple RWUF, describing $f_{\mathrm{sw}, i}$ as an exponential function of soil water matrix with a power $m$ :

$f_{\mathrm{sw}, i}=\left(\frac{\varphi_{\max }-\varphi_{i}}{\varphi_{\max }+\varphi_{\mathrm{sat}}}\right)^{m}$

The value of $m$ has been empirically determined. When the value of $m$ is equal to 1 , our proposed $f_{\mathrm{sw}, i}$ (Eq. (5)) is exactly same as the original one (Eq. (4)). In all other cases, the parameter $m$ represents the nonlinearity of water uptake in relation to soil water potential. We found empirically that $m<1$, and hence, the new RWUF always computes larger values for $f_{\mathrm{sw}}$ than the default RWUF (Eq. (4)). The soil water uptake with the new RWUF is thus than with the default RWUF, especially under low soil water conditions (low soil water matric potential). This agrees with the assumption that desert plants maintain their physiological activities under low matrix potentials (Xu et al., 2007). The introduced parameter $m$ is entirely empirical, and it does not represent a physical process directly.

We first applied the default RWUF (Eq. (4)) to evaluate the performance of CLM against EC data, and next evaluated the effect of the modified RWUF (Eq. (5)) on the model's performance, as shown in a flow diagram (Fig. 2). All model parameters and variables are listed in Table 1.

\subsection{Sensitivity analysis}

The sensitivity of the model to parameter $m$ has been assessed with four simulations: v1, representing the original RWUF (Eq. (4)) with $m=1$, and v2-v4 (Eq. (5)) with $m$ empirically calibrated (v2), and with the empirically calibrated value for $m$ multiplied by 5 (v3) or and by $0.5(\mathrm{v} 4)$.

Among model simulations v1-v4, the total soil depth was unchanged and kept at $3.5 \mathrm{~m}$. To investigate if increasing the soil total depth impacts the model's performance, another simulation (v5) in which the total soil depth was increased to $7.0 \mathrm{~m}$ was carried out. Table 2 lists the specific configurations of all simulations.

\subsection{Statistical analysis}

Energy balance ratio (EBR) (Mahrt, 1998; Gu et al., 1999) was calculated by

$\mathrm{EBR}=\frac{\sum_{i=1}^{n}\left(Q_{\mathrm{le}}+Q_{\mathrm{h}}\right)}{\sum_{i=1}^{n}\left(R_{\mathrm{net}}-G\right)}$ 


\section{Common Land Model}

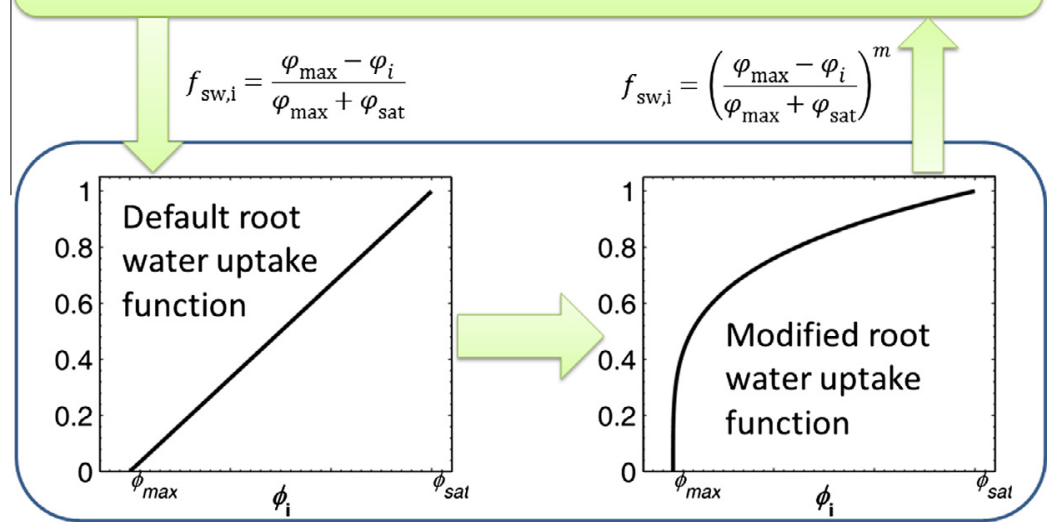

Fig. 2. Flow diagram of the Common Land Model (CLM) with the default root water uptake function (left) and the modified non-linear one (right).

Table 1

List of model parameter and variables appeared in this paper.

\begin{tabular}{|c|c|c|c|}
\hline Symbol & Description & Value & Unit \\
\hline $\bar{O}$ & Mean of observation & & - \\
\hline $\bar{P}$ & Mean of prediction & & - \\
\hline$\varphi_{\max }$ & Soil water potential at wilting point & $-1.5 \times 10^{5}$ & $\mathrm{~mm}$ \\
\hline$\varphi_{\text {sat }}$ & Saturated soil water potential & & $\mathrm{mm}$ \\
\hline$\varphi_{i}$ & Soil water potential & & $\mathrm{mm}$ \\
\hline$b_{0}$ & Intercept of linear regression & & - \\
\hline$b_{\mathrm{s}}$ & Slope of linear regression & & - \\
\hline$D$ & Soil moisture diffusivity & & $\mathrm{m}^{2} \mathrm{~s}^{-1}$ \\
\hline EBR & Energy balance closure & & - \\
\hline$\overline{E_{\mathrm{r}}}$ & Root water uptake & & $\mathrm{m} \mathrm{s}^{-1}$ \\
\hline$E_{\mathrm{x}}$ & Water extraction & & $\mathrm{m} \mathrm{s}^{-1}$ \\
\hline$f_{\text {root }}$ & Root fraction & & - \\
\hline$f_{\text {sw }}$ & Soil water availability & & - \\
\hline $\bar{G}$ & Ground heat flux & & $\mathrm{W} \mathrm{m} \mathrm{m}^{-2}$ \\
\hline$K$ & Hydraulic conductivity & & $\mathrm{m} \mathrm{s}^{-1}$ \\
\hline$m$ & $\begin{array}{l}\text { Parameter in modified root water uptake } \\
\text { function }\end{array}$ & 0.01 & - \\
\hline$n$ & Data number & & - \\
\hline 0 & Observation & & - \\
\hline$P$ & Prediction & & - \\
\hline PFT & Irrigated crop & 25 & $\%$ \\
\hline$\overline{\mathrm{PFT}}$ & Desert shrub & 75 & $\%$ \\
\hline$\overline{Q_{\mathrm{h}}}$ & Sensible heat flux & & $\mathrm{W} \mathrm{m} \mathrm{m}^{-2}$ \\
\hline$Q_{\mathrm{le}}$ & Latent heat flux & & $\mathrm{W} \mathrm{m} \mathrm{m}^{-2}$ \\
\hline$R$ & Correlation coefficient & & - \\
\hline RMSE & Root mean square error & & - \\
\hline$\overline{R_{\text {net }}}$ & Net radiation & & $\mathrm{W} \mathrm{m} \mathrm{m}^{-2}$ \\
\hline$t$ & Time & & - \\
\hline$T$ & Transpiration & & $\mathrm{m} \mathrm{s}^{-1}$ \\
\hline$T_{\mathrm{s}}$ & Soil temperature & & ${ }^{\circ} \mathrm{C}$ \\
\hline$z$ & Soil depth & & $\mathrm{m}$ \\
\hline$\eta_{i}$ & Soil water availability & & - \\
\hline$\theta$ & Soil water content & & $\mathrm{m}^{3} \mathrm{~m}^{-3}$ \\
\hline
\end{tabular}

where $n$ is the number of half hours of data. The use of EBR was able to give an overall evaluation of energy balance closure by averaging over random errors in the half-hour measurements at a flux tower site.

We used linear correlation coefficient $(R)$ and root mean square error (RMSE) between the observed and simulated variables to evaluate the agreement between the simulations and the observations.

$R$ is calculated as:

$$
R=\frac{\sum_{i=1}^{n}\left(O_{i}-\bar{O}\right)\left(P_{i}-\bar{P}\right)}{\sqrt{\sum_{i=1}^{n}\left(O_{i}-\bar{O}\right)^{2} \sum_{i=1}^{n}\left(P_{i}-\bar{P}\right)^{2}}}
$$

where $\bar{O}$ and $\bar{P}$ are the mean values of the observed and modelled fluxes, $O$ and $P$ are the observed and modelled fluxes at time step $i$. The regression coefficients, the slope $\left(b_{\mathrm{s}}\right)$ and the intercept $\left(b_{0}\right)$ were also used to justify the model's performance.

RMSE is calculated as:

RMSE $=\sqrt{\frac{\sum_{i=1}^{n}\left(p_{i}-O_{i}\right)^{2}}{n-1}}$

\section{Results}

\subsection{Meteorological conditions}

Air temperature at FSDE ranges from a minimum of $-35^{\circ} \mathrm{C}$ in the winter to a maximum of $40{ }^{\circ} \mathrm{C}$ in the summer. Relative air humidity is $70-90 \%$ during winter season and $10-60 \%$ (mean value of $40 \%$ ) during the growing season (April-September) (Fig. 3a).

Solar radiation (downward short wave radiation, SWDOWN) exhibits obvious seasonal variations. The peak values of SWDOWN reaches $800-1000 \mathrm{~W} \mathrm{~m}^{-2}$ during growing season and 100 $300 \mathrm{~W} \mathrm{~m}^{-2}$ during winter season. Downward long wave radiation (LWDOWN) shows seasonal variations as well, and ranges between 200 and $400 \mathrm{~W} \mathrm{~m}^{-2}$ (Fig. 3b).

Maximum wind speed fluctuates between $3-10 \mathrm{~m} \mathrm{~s}^{-1}$ and wind speed in the summer was higher than in the winter. The precipitation at the study site was was $185.9 \mathrm{~mm}, 116.3 \mathrm{~mm}$, and $127.6 \mathrm{~mm}$ for 2007, 2008 and 2009, respectively; the average annual rainfall for these 3 years was $143.3 \mathrm{~mm}$. The majority of daily precipitation amounts were less than $5 \mathrm{~mm}$ (Fig. 3c).

\subsection{Energy balance closure and footprint area}

The slope of the linear regression between the observed $Q_{\mathrm{le}}+Q_{\mathrm{h}}$ and $R_{\text {net }}-G$ was 0.85 at the FSDE site. The regression coefficient $(R)$ of the observed $Q_{\mathrm{le}}+Q_{\mathrm{h}}$ and $R_{\text {net }}-G$ was $0.94\left(R^{2}=0.90\right)$ and the intercept was $12.47 \mathrm{~W} \mathrm{~m}^{-2}$ (Fig. 4). These statistical indices in relation with energy balance closure at the studied desert ecosystem EC site are in similar to reported energy balance closure indicators at other sites of the FLUXNET network (Wilson et al., 2002; Li et al., 2005). The EBR at the FSDE site was 0.98, indicating that the bias is small when the annual ratio of total turbulent heat 
Table 2

Five configurations of the CLM model as used in the study. RWUF was referred to root water uptake function and SD was the total soil depth.

\begin{tabular}{ll}
\hline Simulation & Description \\
\hline v1 & Default CLM, with default RWUF and default SD $(3.5 \mathrm{~m})$ \\
v2 & Modified CLM, with $m=0.01$ in the modified RWUF and default \\
& SD $(3.5 \mathrm{~m})$ \\
v3 & $\begin{array}{l}\text { Modified CLM, } m=0.005 \text { in the modified RWUF and default SD } \\
(3.5 \mathrm{~m})\end{array}$ \\
v4 & $\begin{array}{l}\text { Modified CLM, } m=0.05 \text { in the modified RWUF and default SD } \\
(3.5 \mathrm{~m})\end{array}$ \\
v5 & Default CLM, with default RWUF and increased SD $(7.0 \mathrm{~m})$ \\
\hline
\end{tabular}

flux to available energy $\left(R_{\text {net }}-G\right)$ was used to evaluate the energy imbalance.

A footprint analysis (Hsieh et al., 2000) indicates that the fetch length of the observed flux ranged 0-200 m under unstable conditions (Fig. 5b). Under stable conditions, the fetch length ranges from 200 to $5000 \mathrm{~m}$ (Fig. 5a). Overall, the source area of $2500 \mathrm{~m}$ contributes 95\% of the observed fluxes. Fig. 5 also shows that there was no dominant wind direction, with near uniform probability of different directions. Within the footprint area, heterogeneous mosaic patchiness were retrieved using Landsat TM imagery in 2006 based on the method of interactive interpretation and the area consisted of $75 \%$ of desert shrubs with some species of short life grasses and $25 \%$ of irrigated crops. This composition of mosaic land surface corresponded to the land cover types 9 and 4 as defined in the CLM model.

\subsection{Performance of model simulations using default RWUF}

Fig. 6 shows the comparisons between the observed and the simulated diurnal values for four energy components. The default CLM model successfully reproduced $R_{\text {net }}$ using the default version of RWUF (Fig. 6a). The values of $R^{2}$ and RMSE were 0.99 and $20.16 \mathrm{~W} \mathrm{~m}^{-2}$, respectively (Table 3). Unfortunately, $Q_{\mathrm{le}}, Q_{\mathrm{h}}$ and $G$ are all inadequately simulated. For both $Q_{\mathrm{le}}$ and $Q_{h}$, the CLM simulated values were in agreement with the observed fluxes at

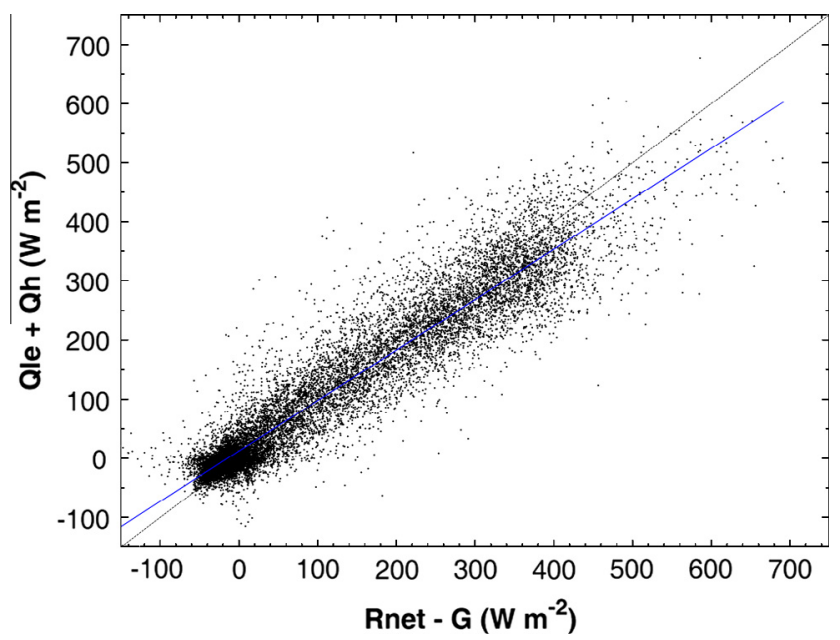

Fig. 4. Energy balance closure at the FSDE eddy covariance site in Central Asia, with the $1: 1$ line (black) and a linear regression (blue). (For interpretation of the references to colour in this figure legend, the reader is referred to the web version of this article.)

nighttime, but the model severely underestimated daytime $Q_{\mathrm{le}}$ and overestimated $Q_{\mathrm{h}}$ (Fig. $6 \mathrm{~b}$ and c). As the residual of $R_{\text {net }}{ }^{-}$ $-\left(Q_{\mathrm{le}}+Q_{\mathrm{h}}\right)$, simulated ground heat flux $(G)$ by the default and modified models were similar, and some discrepancy between the model and the measurements remain because the model assumes energy balance closure, while the measurements have a closure gap. The simulated mean diurnal values of $G$ were smaller at nighttime but greater than the observed at daytime, with the magnitude of $0-40 \mathrm{~W} \mathrm{~m}^{-2}$ (Fig. 6d).

The observed ground heat flux could be impacted by subsurface soil temperature $\left(T_{\mathrm{s}}\right)$. Evaluating the agreement between the simulation and the observation was helpful to identify the cause of the bias in simulated G. Fig. 7a showed the comparison between the observed and the simulated $T_{\mathrm{s}}$. The results showed that the values of $b_{\mathrm{s}}$ and $R^{2}$ were good at 1.0 and 0.84 , respectively, but the
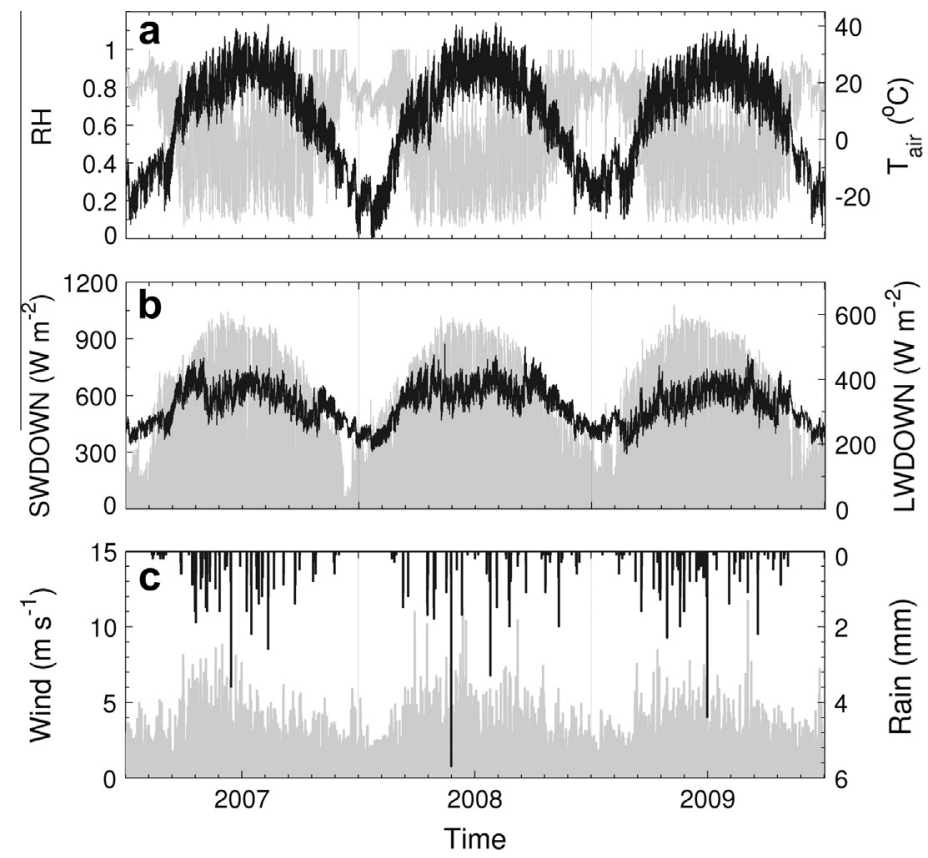

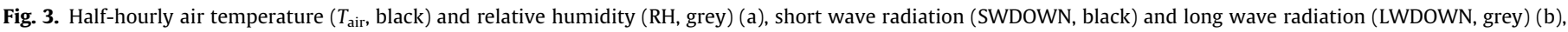
and wind speed (grey) and rain (black) (c) at FSDE site in Central Asia during 2007-2009. 

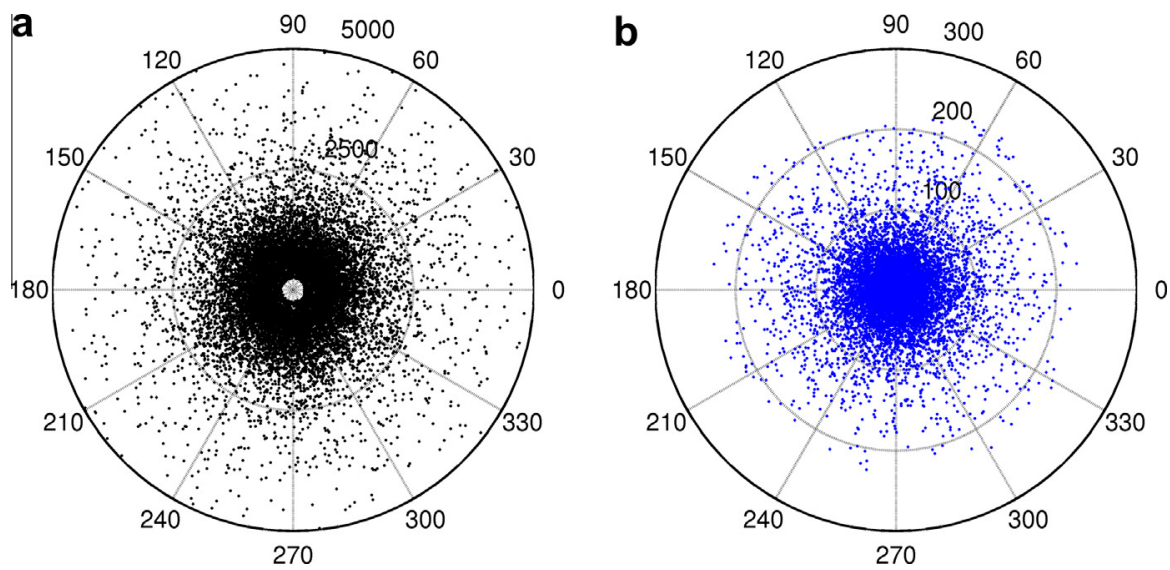

Fig. 5. Footprint area (in metres) of the observed fluxes under stable (a) and unstable (b) conditions at FSDE in Central Asia.
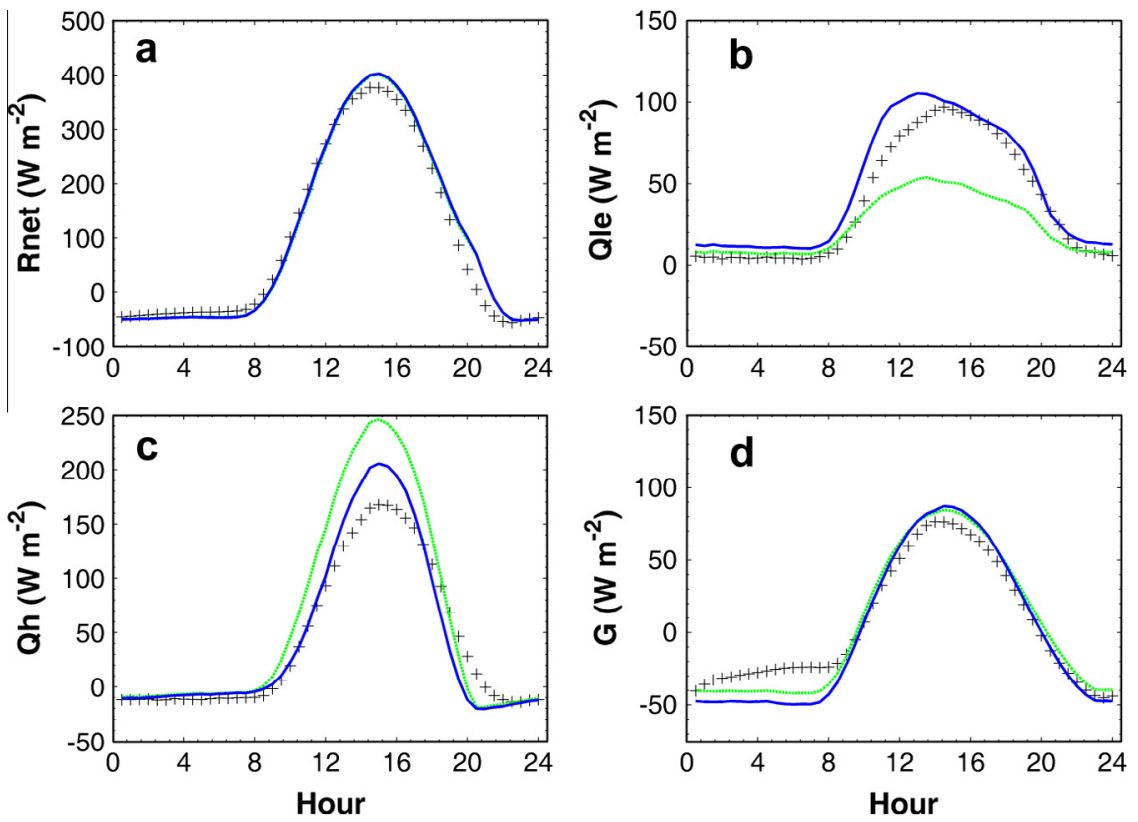

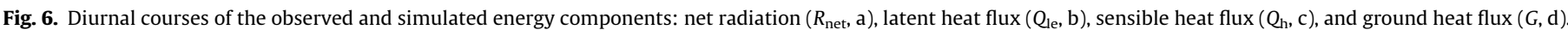

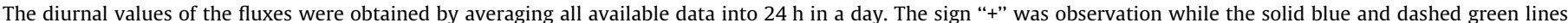

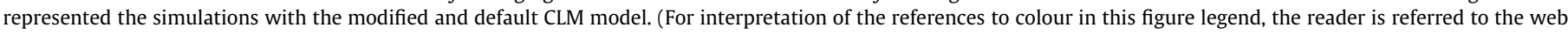
version of this article.)

Table 3

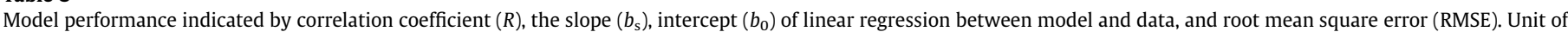
RMSE was ${ }^{\circ} \mathrm{C}$ for surface temperature $\left(T_{\mathrm{s}}\right)$ and $\mathrm{W} \mathrm{m} \mathrm{m}^{-2}$ for all flux variables. $\mathrm{v} 1$ and $\mathrm{v} 2$ are referred to the description in Table 2.

\begin{tabular}{|c|c|c|c|c|c|c|c|c|}
\hline \multirow[t]{2}{*}{ Variables } & \multicolumn{4}{|c|}{ Default CLM (v1) } & \multicolumn{4}{|c|}{ Modified CLM (v2) } \\
\hline & $R$ & RMSE & $b_{\mathrm{s}}$ & $b_{0}$ & $R$ & RMSE & $b_{s}$ & $b_{0}$ \\
\hline Diurnal $R_{\text {net }}$ & 0.99 & 20.16 & 1.04 & 1.7 & 0.99 & 21.33 & 1.04 & 2.6 \\
\hline Diurnal $Q_{\mathrm{le}}$ & 0.98 & 23.18 & 0.49 & 5.7 & 0.98 & 11.03 & 1.03 & 7.5 \\
\hline Diurnal $Q_{h}$ & 0.99 & 36.39 & 1.39 & 3.5 & 0.99 & 18.52 & 1.14 & -2.8 \\
\hline Diurnal G & 0.99 & 9.89 & 1.15 & -0.21 & 0.99 & 13.08 & 1.23 & -5.26 \\
\hline Diurnal $Q_{\mathrm{le}}$ on rainy days & 0.99 & 12.28 & 0.88 & 10.7 & 0.99 & 16.43 & 1 & 13.2 \\
\hline Diurnal $Q_{\mathrm{le}}$ on rainless days & 0.98 & 23.7 & 0.47 & 5.6 & 0.98 & 10.94 & 1.04 & 7.3 \\
\hline Diurnal $Q_{h}$ on rainy days & 0.95 & 30.1 & 1.28 & -12.3 & 0.95 & 23.3 & 1.08 & -12 \\
\hline Diurnal $Q_{h}$ on rainless days & 0.99 & 36.7 & 1.4 & 4 & 0.98 & 18.44 & 1.14 & -2.5 \\
\hline Half-hourly $Q_{\mathrm{le}}$ & 0.64 & 45.13 & 0.48 & 6.1 & 0.82 & 34.48 & 0.84 & 14.9 \\
\hline Half-hourly $Q_{\mathrm{h}}$ & 0.92 & 52.73 & 1.27 & 8.6 & 0.9 & 40.53 & 1.01 & 2.6 \\
\hline Half-hourly $T_{s}$ & 0.92 & 4.56 & 1 & 2.8 & 0.92 & 4.72 & 1.03 & 2.3 \\
\hline
\end{tabular}




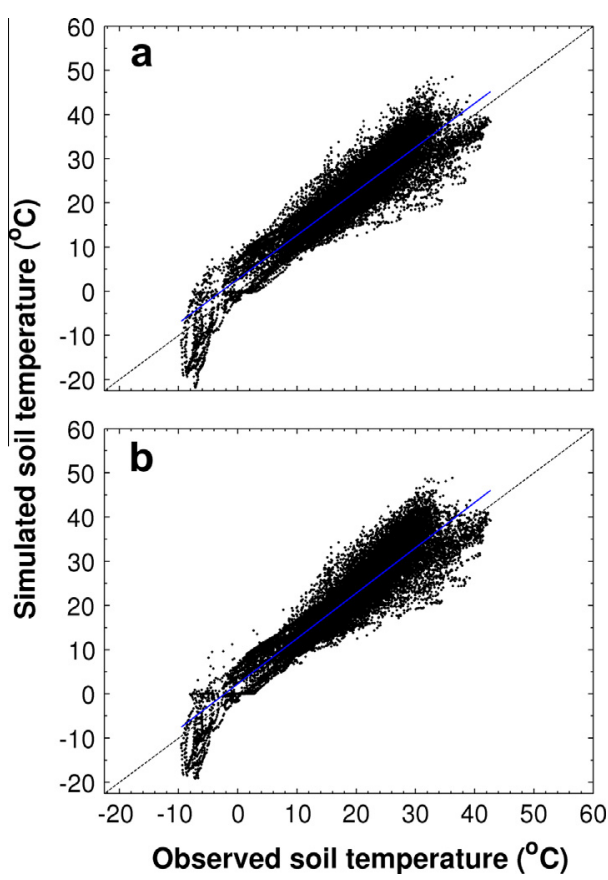

Fig. 7. Comparison between the observed and the simulated sub-surface soil temperatures with the CLM model using the default (a) and modified (b) root water uptake function. The solid blue line represented the linear regression between the simulation and the observation, and the dashed was 1:1 line. (For interpretation of the references to colour in this figure legend, the reader is referred to the web version of this article.)

RMSE was high of $4.56{ }^{\circ} \mathrm{C}$. This result suggests that the bias in subsurface soil temperature may partially cause the error in $G$.

Focusing on $Q_{\mathrm{le}}$ and $Q_{\mathrm{h}}$, the observed fluxes were categorized into two groups in terms of rainy and rainless days and averaged to the diurnal dynamics. The default CLM model reproduces the diurnal patterns of both $Q_{\mathrm{le}}$ and $Q_{\mathrm{h}}$ on rainy days (Fig. 8a and c), but the CLM model with default RWUF (v1) severely underestimates $Q_{\mathrm{le}}$ and overestimates $Q_{\mathrm{h}}$ at daytime on rainless days. Especially around noon, the simulated $Q_{\mathrm{le}}$ was less than half of the observed values only and the simulated $Q_{h}$ was two third greater than the observations (Fig. $8 \mathrm{~b}$ and $\mathrm{d}$ ).

Fig. 9a and c presents scatter plots of observed half-hourly fluxes to the atmosphere $\left(Q_{\mathrm{le}}\right.$ and $\left.Q_{h}\right)$ and simulated values with the CLM model using the default RWUF. The slopes of the linear regression between the simulated and the observed $Q_{\mathrm{le}}$ and $Q_{\mathrm{h}}$ with default CLM model were significantly different from $1(0.48$ for $Q_{\mathrm{le}}$ and 1.27 for $Q_{\mathrm{h}}$, Table 3), indicating that the CLM with the default RWUF (Eq. (4)) greatly underestimated $Q_{\text {le }}$ and overestimated $Q_{\mathrm{h}}$ at FSDE site. Driven by high solar radiation, high temperature and small rain during the growing season (Li et al., 2011a), atmospheric evaporative demand was substantially strong at the studied site. This implied that potential evapotranspiration simulated by the model was large. However, the CLM model severely underestimated $Q_{\mathrm{le}}$ on rainless days.

The availability of soil water could constrain $Q_{\text {le }}$ by the effects on either plant stomatal conductance or the amount of water uptake by roots. Previous literature reported that the stomatal conductance of the desert shrub in the studied area did not significantly respond to rainfall or subsurface soil water availability (Xu et al., 2007). Therefore, the model's insufficiency in $Q_{\text {le }}$ may result from the root water uptake process, similar to other versions of LSMs' weakness in application to forest ecosystems in dry period (Zheng and Wang, 2007). In the next section, we demonstrate the impact of a modified RWUF on the CLM's performance at the FSDE site.

\subsection{Impact of RWUF on the model's performance}

With the newly proposed RWUF (Eq. (5)), the CLM model produces similar results of $R_{\text {net }}$ and $G$ like as produced by the default model (Fig. 6a and d), but $Q_{\mathrm{le}}$ and $Q_{\mathrm{h}}$ are significantly improved (Fig. 6b and c). Consequently, the simulated $Q_{\mathrm{le}}$ and $Q_{\mathrm{h}}$ with the modified model agreed well with the diurnal courses of the
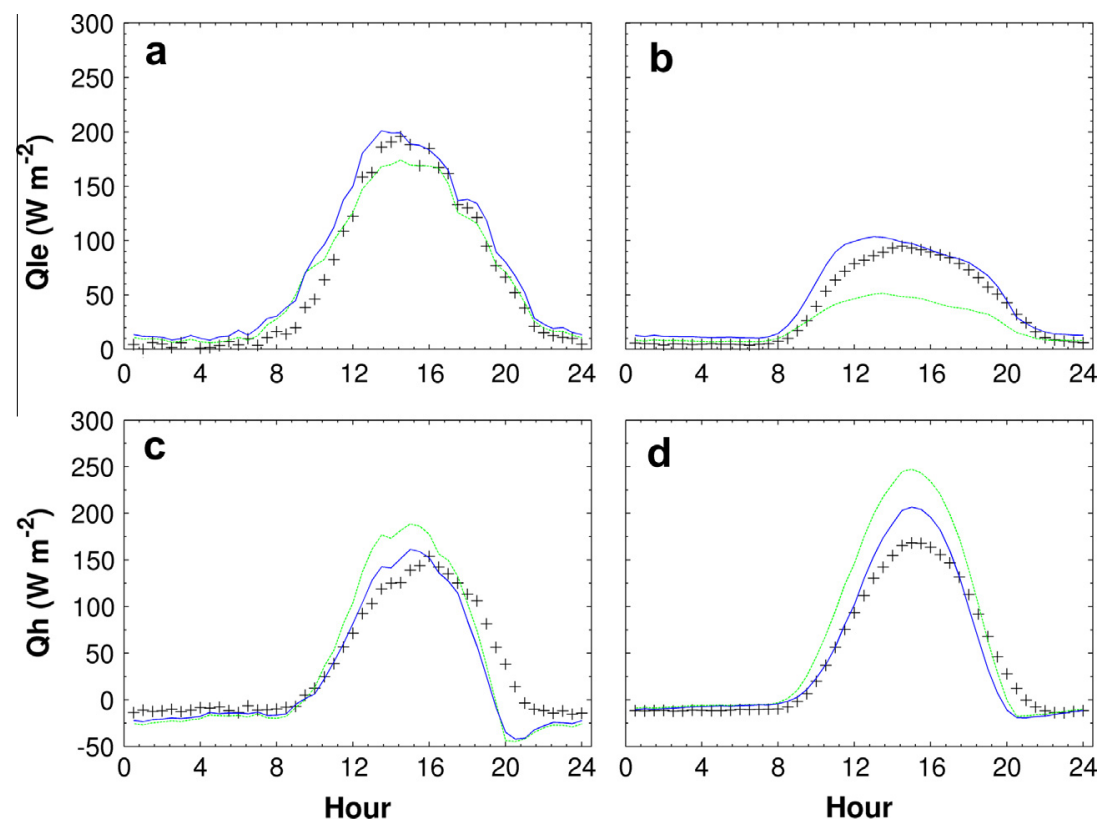

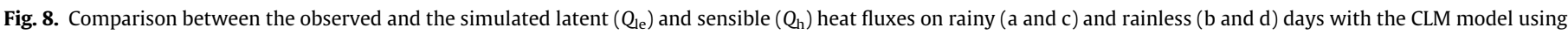

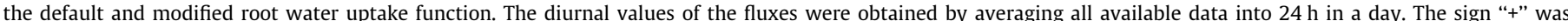

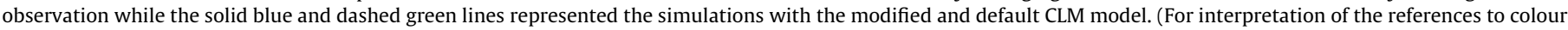
in this figure legend, the reader is referred to the web version of this article.) 

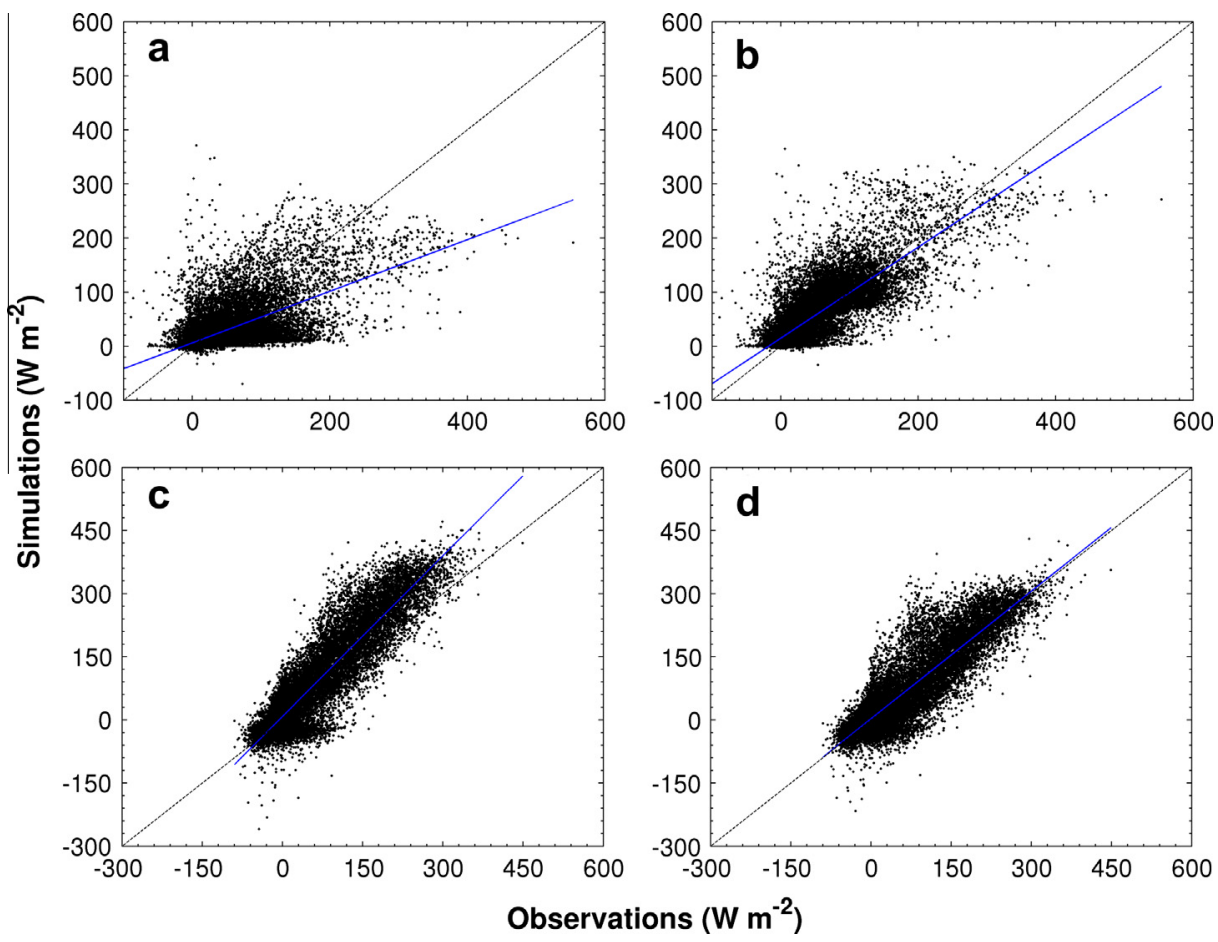

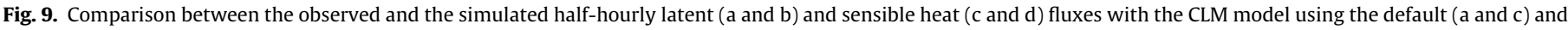

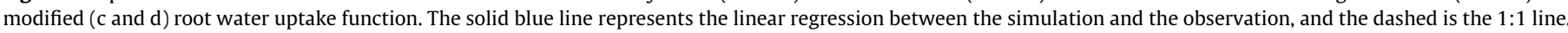
(For interpretation of the references to colour in this figure legend, the reader is referred to the web version of this article.)

observed fluxes, although the model still slightly overestimated $Q_{\text {le }}$ and $Q_{\mathrm{h}}$ around noon.

Compared with Fig. 7a, Fig. 7b showed that the CLM with a modified RWUF did not affect predicted subsurface soil moisture. The resulting slope, $R^{2}$, and RMSE (Table 3 ) were similar to those of the default model.

The new RWUF improves the simulation of both $Q_{\mathrm{le}}$ and $Q_{\mathrm{h}}$ on rainless days (Fig. 8b and d), while the simulation of $Q_{\mathrm{le}}$ and $Q_{\mathrm{h}}$ on rainy days is only slightly changed (Fig. 8a and c).

The modification of RWUF also increases the agreement between the model and the observations for half-hourly $Q_{\mathrm{le}}$ and $Q_{\mathrm{h}}$ as indicated by the slope of linear regression, $R^{2}$ and RMSE. The slope for $Q_{\mathrm{le}}$ increases from 0.48 to 0.84 and that for $Q_{\mathrm{h}}$ decreases from 1.27 to 1.01 (Table 3). The slope values for $Q_{\mathrm{le}}$ and $Q_{\mathrm{h}}$ are closer to 1 . The values of RMSE for both $Q_{\mathrm{le}}$ and $Q_{\mathrm{h}}$ decrease from $45.13 \mathrm{~W} \mathrm{~m}^{-2}$ to $34.48 \mathrm{~W} \mathrm{~m}^{-2}$ for $Q_{\mathrm{le}}$ and from $52.73 \mathrm{~W} \mathrm{~m}^{-2}$ to $40.53 \mathrm{~W} \mathrm{~m}^{-2}$ for $Q_{\mathrm{h}}$. For $Q_{\mathrm{le}}$, the modified CLM model also improves the correlation coefficient $(R)$ from 0.64 to 0.82 (Fig. 9 and Table 3 ).

The improvement of the CLM's performance for $Q_{\mathrm{le}}$ (and $Q_{h}$ ) is due to the change of a linear into a non-linear root water uptake response to soil water potential (see Fig. 10). The optimized value of $m<1$ indicates a more efficient root water uptake than the default. The larger $f_{\mathrm{sw}}$ in the modified model increases the simulated $Q_{\mathrm{le}}$, especially for dry soil was. Due to the energy balance, the increase in simulated $Q_{\mathrm{le}}$ decreases simulated $Q_{\mathrm{h}}$. Thus the performance of CLM in application to CA desert shrub ecosystem is significantly improved with the modified root uptake function.

\subsection{Sensitivity of CLM to the parameter $m$}

The value the parameter $m$ was empirically determined as 0.01 in v2 simulation. Simulated diurnal $Q_{\mathrm{le}}$ and $Q_{\mathrm{h}}$ fluxes by decreasing the value of $m$ to 0.005 (v3) do not differ from v2 (Fig. 11). In contrast, simulated diurnal $Q_{\mathrm{le}}$ and $Q_{\mathrm{h}}$ after increasing $m$ to 0.05 (v4) are lower than those by v2. Increasing the rooting depth SD to

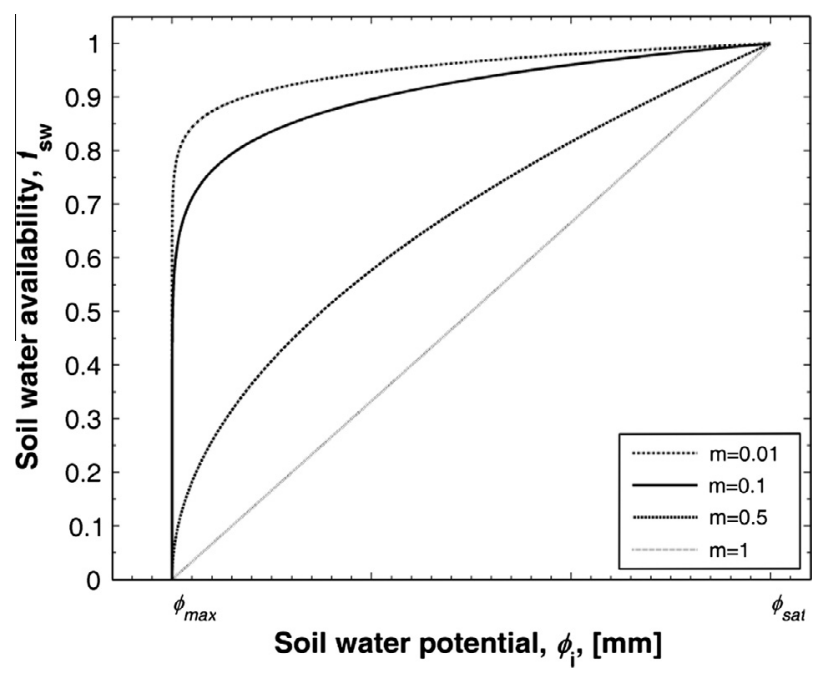

Fig. 10. Comparison between the default and modified root water uptake functions The linear line represented the default root water uptake function in CLM. The nonlinear curve cluster illustrated the modified root water uptake efficiency as a function of soil water potential $\left(\varphi_{i}\right)$ in dependence with the value of power $m$. Calculated root water uptake efficiency using the modified root water uptake function with $m<1$ always produced higher value than that using the default

$7.0 \mathrm{~m}$ (v5) does not improve the CLM model's performance for both $Q_{\mathrm{le}}$ and $Q_{\mathrm{h}}$. Simulated diurnal fluxes of $Q_{\mathrm{le}}$ and $Q_{\mathrm{h}}$ are quite similar to the default CLM with SD of $3.5 \mathrm{~m}$ (Fig. 11).

The performance indicators $R$ and RMSE, with hour-hourly fluxes for simulations v1-v5 are shown in Fig. 12. Decreasing $m$ (v3) does not affect the model's performance, while increasing $m$ to 0.05 (v4) decreases the model's performance compared to v2 ( $m=0.01$ ), but the performance is still better than the default simulation (v1). Doubling the total soil depth only (v5) does not have a significant effect on the simulation of both $Q_{\mathrm{le}}$ and $Q_{\mathrm{h}}$ (Fig. 12). 

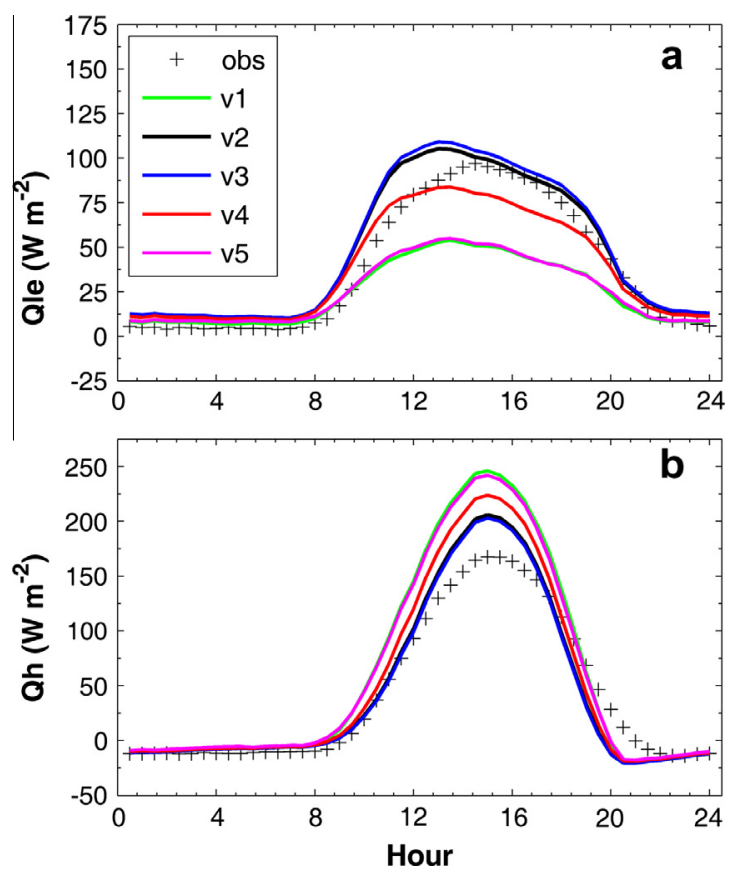

Fig. 11. Sensitivity of the simulated mean diurnal patterns of latent (a) and sensible (b) heat fluxes to the parameter $m$ in the modified root water uptake function and the total soil depth. Simulations v1-v5 are referred to the Table 2.

These sensitivity analyses indicate that increasing the total soil depth only does not to improve the simulation of $Q_{\mathrm{le}}$. In contrast, modifying the original RWUF with a linear function of soil water potential to one with exponential function (with power $m$ ) significantly improved the performances for both $Q_{\mathrm{le}}$ and $Q_{\mathrm{h}}$ fluxes, although the effect of the modified RWUF to the model's performance depended on the parameterization of the value $m$.

\section{Discussion}

Arid and semiarid (or dryland) regions cover approximately $45 \%$ of the global terrestrial land surfaces (Asner et al., 2003; Lal, 2004). These areas are considered important in global environmental research (Hastings et al., 2005; Bruemmer et al., 2008). One unique feature of dryland ecosystems, including the Central Asia desert, is that sensible heat dominates the energy budget (Unland et al., 1996). At FSDE site, mean maximum daily latent heat was about $70 \mathrm{~W} \mathrm{~m}^{-2}$ lower than the maximum sensible heat flux. The energy balance closure observed in the studied site was in good agreement with that at other FLUXNET sites (Wilson et al., 2002), or other desert ecosystems, for example, Burkina Faso in West Africa (Bruemmer et al., 2008), or Baja California, Peninsula, Mexico (Hastings et al., 2005).

For global ecological modelling, desert ecosystems are important because of their vast spatial extend, but there are only few studies of energy, water and $\mathrm{CO}_{2}$ in these ecosystems (Hastings et al., 2005; Bruemmer et al., 2008). In particular, the performance of LSMs at desert ecosystem sites has been largely unknown. At FSDE in CA, the dominated role of sensible heat in energy budget at FSDE was exaggerated in the CLM model, causing an underestimate of the latent heat flux. To overcome the weakness in the CLM model, likely in other LSMs, a simply empirical RWUF was used instead of the default one in CLM and significantly corrected the bias in latent heat flux. The newly proposed function considered roots of desert shrubs were able to dynamically respond to varying soil wetness and more efficiently to absorb water from soil layers, especially under low soil water conditions. This mechanism of desert plants in CA was associated with the long-term adaptation to extremely dry environment (Xu et al., 2007; Xu and Li, 2008), which enables desert plants being able to maximize the use of limited water from soil. The selected root function may affect the outcome of simulations of moisture recycling, the sustainability of plant physiological activities (transpiration and photosynthesis) and the regional climate (Lee et al., 2005). This research indicates that a suitable representation of root functioning in responding
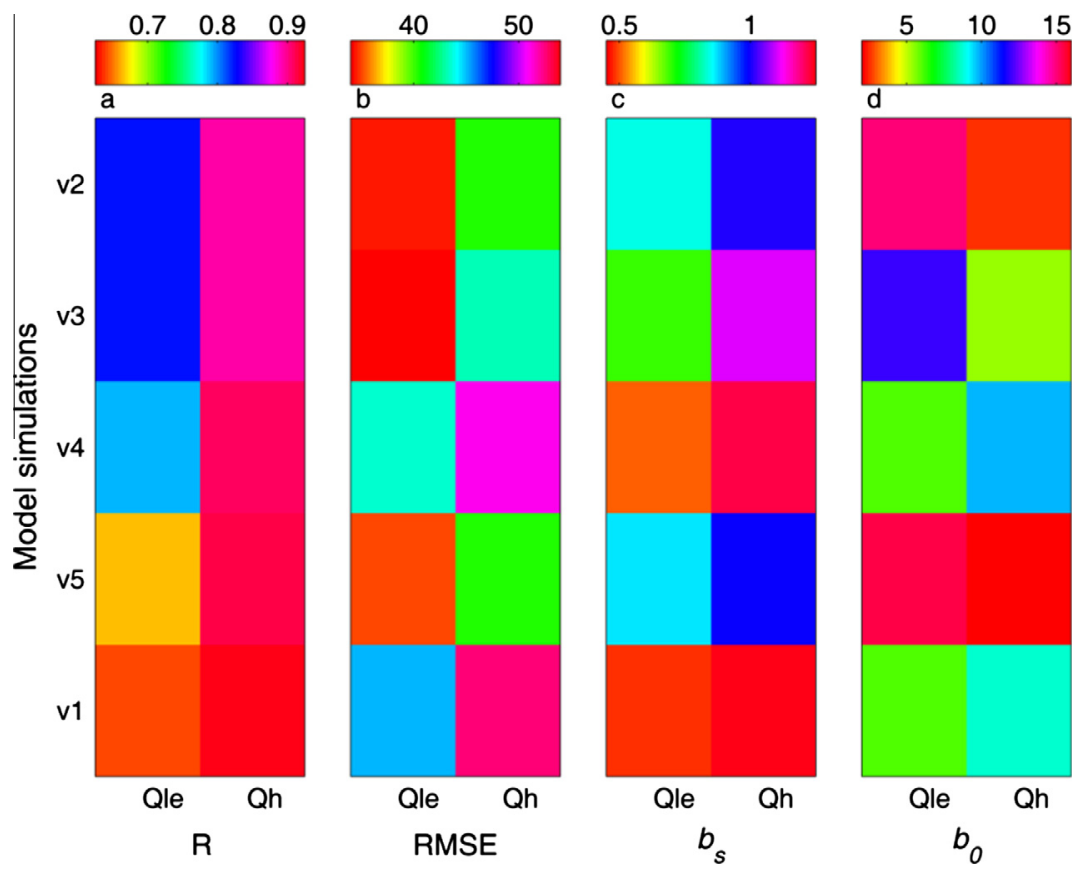

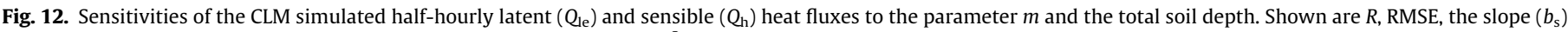
and interception $\left(b_{0}\right)$ for all data combined. The units of RMSE are $\mathrm{W} \mathrm{m}^{-2}$. Simulations v1-v5 refer to the simulation options listed in Table 2. 
to soil wetness in the CLM model was necessary for the correct simulation of energy and water vapour fluxes in CA desert shrub ecosystems. Although the modified RWUF was essentially established on the empirical basis, it supported the previous hypothesis on desert plants' water use strategy and improved the performance of the CLM model significantly in desert environment.

Roots are the primary pathway for plants to uptake water and nutrients from soil. They connect the soil environment to the atmosphere through water, energy and mass exchanges between plant canopy and atmosphere (Feddes et al., 2001). Better understanding and generalizing root water uptake function are important to improve the predictability of LSMs. Considerable studies have attempted to propose universal RWUFs which can be used for various water conditions and ecosystems, but none was found to be successful. Drought can occur in different patterns. For example, seasonal drought is a dominant type of drought in Amazon rainforest (Baker et al., 2008; Li et al., 2012). In contrast, Central Asia is characterized as chronic drought. Different ecosystem may show different strategy to adapt for different drought. In Amazon rainforest, hydraulic redistribution is an effective mechanism to maintain transpiration (Oliveira et al., 2005; Lee et al., 2005). In Central Asia, higher root water uptake efficiency may be a strategy for desert shrubs to adapt for environment (Xu et al., 2007). We have addressed this issue at a representative desert shrub site in Central Asia and introducing this mechanism into the RWUF in the CLM model demonstrated its significance for the estimation of evapotranspiration. The next step is to investigate its effects on regional evapotranspiration estimation and hydrological budget.

\section{Conclusion}

To the best of our knowledge, this study provided the first evaluation of LSMs for energy and water vapour exchanges in application to desert ecosystem in Central Asia area. From this study, the following is concluded:

- The default CLM model was able to well reproduce net radiation, however, underestimated latent heat flux and overestimated sensible heat flux. The simulated latent heat flux was only around half of the observations while the simulated sensible heat flux was $27 \%$ higher than the observed values.

- A modified empirical RWUF, describing root water uptake efficiency as an exponential function of soil water potential matrix with a power $m$, was applied to the CLM model, significantly improved the model's performance for both latent and sensible heat fluxes. This implies that root water uptake process in CLM could be better improved by increasing the efficiency of water uptake by roots.

\section{Acknowledgements}

This work is financially supported by one of National Basic Research Program of China (Grant No. 2009CB825105) and the "Hundred Talent" Project of Chinese Academy of Sciences (Grant No. Y174051001) and the National Natural Science Foundation of China (Grant No. 41171094). The authors are grateful for Prof. Y. Li for providing the EC data.

\section{References}

Asner, G.P., Archer, S., Hughes, R.F., et al., 2003. Net changes in regional woody vegetation cover and carbon storage in Texas Drylands, 1937-1999. Global Change Biology 9 (3), 316-335.
Baker, I.T., Prihodko, L., Denning, A.S., et al., 2008. Seasonal drought stress in the Amazon: reconciling models and observations. Journal of Geophysical Research - Biogeosciences 113.

Baldocchi, D., Falge, E., Gu, L.H., et al., 2001. FLUXNET: a new tool to study the temporal and spatial variability of ecosystem-scale carbon dioxide, water vapor, and energy flux densities. Bulletin of the American Meteorological Society 82 (11), 2415-2434.

Bonan, G.B., 1996. A Land Surface Model (LSM Version 1.0) for Ecological Hydrological, and Atmospheric Studies: Technical Description and User's Guide. NCAR Tech. Note NCAR/TN-417+STR, 150 pp.

Bonan, G.B., Lawrence, P.J., Oleson, K.W., et al., 2011. Improving canopy processes in the Community Land Model version 4 (CLM4) using global flux fields empirically inferred from FLUXNET data. Journal of Geophysical Research Biogeosciences 116.

Bruemmer, C., Falk, U., Papen, H., et al., 2008. Diurnal, seasonal, and interannual variation in carbon dioxide and eneroy exchange in shrub savanna in Burkina Faso (West Africa). Journal of Geophysical Research - Biogeosciences 113 (G2).

Choi, M., Lee, S.O., Kwon, H., 2010. Understanding of the Common Land Mode performance for water and energy fluxes in a farmland during the growing season in Korea. Hydrological Processes 24 (8), 1063-1071.

Ciais, P., Reichstein, M., Viovy, N., et al., 2005. Europe-wide reduction in primary productivity caused by the heat and drought in 2003. Nature 437 (7058), 529533.

Dai, Y.J., Dickinson, R.E., Wang, Y.P., 2004. A two-big-leaf model for canopy temperature, photosynthesis, and stomatal conductance. Journal of Climate 17 (12), 2281-2299.

Dai, Y.J., Zeng, Q.C., 1997. A land surface model (IAP94) for climate studies, Part I: formulation and validation in off-line experiments. Advances in Atmospheric Sciences 14, 433-460.

Dai, Y.J., Zeng, X.B., Dickinson, R.E., et al., 2003. The Common Land Model. Bulletin of the American Meteorological Society 84 (8), 1013-+.

Davidson, E., Lefebvre, P.A., Brando, P.M., et al., 2011. Carbon inputs and water uptake in deep soils of an eastern Amazon forest. Forest Science 57 (1), 51-58.

Dickinson, R.E., Henderson-Sellers, A., Kennedy, P.J., et al., 1993. BiosphereAtmosphere Transfer Scheme (BATS) Version 1e as Coupled to Community Climate Model. NCAR Tech. Note NCAR/TN-387+STR, p. 72.

Feddes, R.A., Hoff, H., Bruen, M., et al., 2001. Modeling root water uptake in hydrological and climate models. Bulletin of the American Meteorological Society 82 (12), 2797-2809.

Gu, J.J., Smith, E.A., Merritt, J.D., 1999. Testing energy balance closure with GOES retrieved net radiation and in situ measured eddy correlation fluxes in BOREAS. Journal of Geophysical Research - Atmospheres 104 (D22), 27881-27893.

Hastings, S.J., Oechel, W.C., Muhlia-Melo, A., 2005. Diurnal, seasonal and annual variation in the net ecosystem $\mathrm{CO}_{2}$ exchange of a desert shrub community (Sarcocaulescent) in Baja California, Mexico. Global Change Biology 11 (6), $927-$ 939.

Hsieh, C.I., Katul, G.C., Chi, T., 2000. An approximate analytical model for footprint estimation of scaler fluxes in thermally stratified atmospheric flows. Advances in Water Resources 23 (7), 765-772.

Idso, S.B., 1981. A set of equations for full spectrum and 8-mu-m to 14-mu-m and $10.5-\mathrm{mu}-\mathrm{m}$ to $12.5-\mathrm{mu}-\mathrm{m}$ thermal-radiation from cloudless skies. Water Resources Research 17 (2), 295-304.

Jackson, R.B., Sperry, J.S, Dawson, T.E., 2000. Root water uptake and transport: using physiological processes in global predictions. Trends in Plant Science 5 (11), 482-488.

Kowalczyk, E.A., Wang, Y.P., Law, R.M., et al., 2006. The CSIRO Atmosphere Biosphere Land Exchange (CABLE) Model for Use in Climate Models and as an Offline Model. CSIRO Marine and Atmospheric Research, Paper 013, p. 37.

Krinner, G., Viovy, N., de Noblet-Ducoudre, N., et al., 2005. A dynamic globa vegetation model for studies of the coupled atmosphere-biosphere system. Global Biogeochemical Cycles 19 (1).

Kustas, W.P., Humes, K.S., Norman, J.M., et al., 1996. Single- and dual-source modeling of surface energy fluxes with radiometric surface temperature. Journal of Applied Meteorology 35 (1), 110-121.

Lai, C.T., Katul, G., 2000. The dynamic role of root-water uptake in coupling potential to actual transpiration. Advances in Water Resources 23 (4), 427-439.

Lal, R., 2004. Carbon sequestration in dryland ecosystems. Environmental Management 33 (4), 528-544.

Lee, J.E., Oliveira, R.S., Dawson, T.E., et al., 2005. Root functioning modifies seasonal climate. Proceedings of the National Academy of Sciences of the United States of America 102 (49), 17576-17581.

Li, K.Y., De Jong, R., Coe, M.T., et al., 2006. Root-water-uptake based upon a new water stress reduction and an asymptotic root distribution function. Earth Interactions 10 .

Li, L., Luo, G., Chen, X., et al., 2011a. Modelling evapotranspiration in a Central Asian desert ecosystem. Ecological Modelling 222 (20-22), 3680-3691.

Li, L., Vuichard, N., Viovy, N., et al., 2011b. Importance of crop varieties and management practices: evaluation of a process-based model for simulating $\mathrm{CO}_{2}$ and $\mathrm{H}_{2} \mathrm{O}$ fluxes at five European maize (Zea mays L.) sites. Biogeosciences 8 (6), $1721-1736$.

Li, L., Wang, Y.P., Yu, Q., et al., 2012. Improving the responses of the Australian community land surface model (CABLE) to seasonal drought. Journal of Geophysical Research - Biogeosciences. http://dx.doi.org/10.1029/ 2012JG002038.

Li, Z.Q., Yu, G.R., Wen, X.F., et al., 2005. Energy balance closure at ChinaFLUX sites. Science in China Series D - Earth Sciences 48, 51-62. 
Mahrt, L., 1998. Flux sampling errors for aircraft and towers. Journal of Atmospheric and Oceanic Technology 15 (2), 416-429.

Maxwell, R.M., Miller, N.L., 2005. Development of a coupled land surface and groundwater model. Journal of Hydrometeorology 6 (3), 233-247.

McElrone, A.J., Pockman, W.T., Martinez-Vilalta, J., et al., 2004. Variation in xylem structure and function in stems and roots of trees to $20 \mathrm{~m}$ depth. New Phytologist 163 (3), 507-517.

Oleson, K.W., Niu, G.Y., Yang, Z.L., et al., 2008. Improvements to the Community Land Model and their impact on the hydrological cycle. Journal of Geophysica Research - Biogeosciences 113 (G1).

Oliveira, R.S., Dawson, T.E., Burgess, S.S.O., et al., 2005. Hydraulic redistribution in three Amazonian trees. Oecologia 145, 354-363.

Philip, J.R., 1975. Evaporation and moisture and heat fields in the soil. Journal of Meteorology 14, 354-366.

Ridler, M.E., Sandholt, I., Butts, M., et al., 2012. Calibrating a soil-vegetationatmosphere transfer model with remote sensing estimates of surface temperature and soil surface moisture in a semi arid environment. Journal of Hydrology 436-437, 1-12.

Rihani, J.F., Maxwell, R.M., Chow, F.K., 2010. Coupling groundwater and land surface processes: idealized simulations to identify effects of terrain and subsurface heterogeneity on land surface energy fluxes. Water Resources Research 46.

Saleska, S.R., Miller, S.D., Matross, D.M., et al., 2003. Carbon in Amazon forests: unexpected seasonal fluxes and disturbance-induced losses. Science 302 (5650), 1554-1557.

Schwalm, C.R., Williams, C.A., Schaefer, K., et al., 2010. A model-data intercomparison of $\mathrm{CO}_{2}$ exchange across North America: results from the North American Carbon Program site synthesis. Journal of Geophysical Research - Biogeosciences 115

Sellers, P.J., Mintz, Y., Sud, Y.C., et al., 1986. A simple biosphere model (SiB) for use within general-circulation models. Journal of the Atmospheric Sciences 43 (6), 505-531.

Sellers, P.J., Randall, D.A., Collatz, G.J., et al., 1996. A revised land surface parameterization (SiB2) for atmospheric GCMs. 1. Model formulation. Journal of Climate 9 (4), 676-705.

Steiner, A.L., Pal, J.S., Giorgi, F., et al., 2005. The coupling of the Common Land Mode (CLMO) to a regional climate model (RegCM). Theoretical and Applied Climatology 82 (3-4), 225-243.

Stockli, R., Lawrence, D.M., Niu, G.Y., et al., 2008. Use of FLUXNET in the community land model development. Journal of Geophysical Research - Biogeosciences 113 (G1).
Susiluoto, S., Berninger, F., 2007. Interactions between morphological and physiological drought responses in Eucalyptus microtheca. Silva Fennica 41 (2), 221-233.

Unland, H.E., Houser, P.R., Shuttleworth, W.J., et al., 1996. Surface flux measurement and modeling at a semi-arid Sonoran Desert site. Agricultural and Forest Meteorology 82 (1-4), 119-153.

van der Tol, C., 2012. Validation of remote sensing of bare soil ground heat flux. Remote Sensing of Environment 121, 275-286.

Wang, T., Brender, P., Ciais, P., et al., 2012. State-dependent errors in a land surface model across biomes inferred from eddy covariance observations on multiple timescales. Ecological Modelling 246, 11-25.

Wang, Y.P., Law, R.M., Pak, B., 2010. A global model of carbon, nitrogen and phosphorus cycles for the terrestrial biosphere. Biogeosciences 7 (7), 22612282 .

Webb, E.K., Pearman, G.I., Leuning, R., 1980. Correction of flux measurements for density effects due to heat and water-vapor transfer. Quarterly Journal of the Royal Meteorological Society 106 (447), 85-100.

Williams, M., Richardson, A.D., Reichstein, M., et al., 2009. Improving land surface models with FLUXNET data. Biogeosciences 6 (7), 1341-1359.

Wilson, K., Goldstein, A., Falge, E., et al., 2002. Energy balance closure at FLUXNET sites. Agricultural and Forest Meteorology 113 (1-4), 223-243.

Xu, G.Q., Li, Y., 2008. Rooting depth and leaf hydraulic conductance in the xeric tree Haloxyolon ammodendron growing at sites of contrasting soil texture. Functional Plant Biology 35 (12), 1234-1242.

Xu, H., Li, Y., Xu, G., et al., 2007. Ecophysiological response and morphological adjustment of two Central Asian desert shrubs towards variation in summer precipitation. Plant Cell and Environment 30 (4), 399-409.

Zampieri, M., Serpetzoglou, E., Anagnostou, E.N., et al., 2012. Improving the representation of river-groundwater interactions in land surface modeling at the regional scale: observational evidence and parameterization applied in the Community Land Model. Journal of Hydrology 420, 72-86.

Zeng, X.B., Shaikh, M., Dai, Y.J., et al., 2002. Coupling of the common land model to the NCAR community climate model. Journal of Climate 15 (14), 1832-1854.

Zheng, Z., Wang, G., 2007. Modeling the dynamic root water uptake and its hydrological impact at the Reserva Jaru site in Amazonia. Journal of Geophysical Research - Biogeosciences 112 (G4).

Zhou, X., Zhang, Y., Wang, Y., et al., 2012. Benchmarking global land surface models against the observed mean annual runoff from 150 large basins. Journal of Hydrology 470-471, 269-279. 